\title{
A standard proposal for biological resources centres
}

\author{
Anabela Martins and Nelson Lima \\ Centre of Biological Engineering, University of Minho, Braga, Portugal, and \\ Paulo Sampaio \\ Department of Production and Systems, University of Minho, Braga, Portugal
}

\begin{abstract}
Purpose - The purpose of this paper is to contribute to develop a standard providing requirements for managing the quality and competence of the biological resource centres (BRC).

Design/methodology/approach - The methodology for the standard setting was based on the principles of credibility, transparency, alignment and consistency. A justification study was performed to establish its objectives and scope, avoid overlap and prevent the risks in implementation. International documents providing rules for standard development were taken into consideration. Requirements were assembled from several standards and participation of interested parties was promoted.

Findings - No relevant international document exists covering fundamental issues for BRC operation. It is possible to develop a consistent and aligned standard, under a credible and transparent process that fits BRC purposes.

Practical implications - This standard will strengthen the BRC technical competence increasing its capability to provide authenticated high-quality biological materials - a crucial factor for biotechnological developments in the fields of health, agriculture and environment. It will serve as a basis for the BRC compliance assessment and the launch pad for establishing the global BRC network.
\end{abstract}

Originality/value - Original paper.

Keywords Certification, Accreditation, Standardization, Biological resource centres, Culture collection, Standard setting, GBRCN

Paper type Research paper

\section{Introduction}

The invention of the microscope in the seventeenth century opened a window to a new and fascinating universe that has boosted the development of life sciences: the world of microbes. If making microbes visible was a huge achievement, to preserve them with their unique characteristics for the long term, is an even greater challenge which culture collections (CC) first embraced 120 years ago (Santos and Lima, 2001).

The existing 693 service $\mathrm{CC}$ in 71 countries and regions (www.wfcc.info/ccinfo/) plays a vital role, by expertly preserving biological material (BM) in ex-situ repositories and making it promptly available to several users such as industry and services, R\&D in biotechnology and teaching (Lima, 2007). They have the responsibility of maintaining BM that fulfil characteristics claimed in their catalogues: in order to assure reliable results in research based on supplied samples and reproducibility in industrial processes, as well as, preserving biodiversity that is being rapidly destroyed (Boundy-Mills, 2012). It is crucial that BM is preserved in the same state in which it was isolated and that the preserved cultures are representative of species in nature. Also, preserved strains must maintain the characteristics that made them of interest to preserve in the first case (e.g. enzyme production, mycotoxins, antibiotics, etc.).

$\mathrm{CC}$ were formerly considered as individual research initiatives hosted by universities and research institutes. However, the rise in the scientific and biotechnological importance of BM along with an increased awareness by governments of the necessity for protection of the 
IJQRM

34,2

microbial materials origin and the implementation of mechanisms to assure biosecurity, has resulted in a global understanding of the need to create stable and well managed operations inside CC, assuring that access, maintenance and provision of authenticated microbial strains of known origin are in operation.

In the coming years, biodiversity and omics will be the source of a "tremendous amount of biological material" and "big data" (OECD, 2001) both crucial to the development of R\&D in life sciences and biotechnology, making the role of $\mathrm{CC}$ even more critical.

OECD (2001) recommended the creation of a CC network, the Global biological resource centres (BRC) network - more details about this network can be found at GBRCN, www. gbrcn.com. Each BRC member should work under certification or accreditation schemes based on scientifically acceptable international criteria, supported by national governments (OECD, 2001) with an audit programme established to evaluate the BRC compliance with requirements (OECD, 2004).

A normative document providing requirements for the $\mathrm{BRC}$ management system, auditable, enabling the $\mathrm{BRC}$ certification or accreditation, must therefore be put in place.

\section{Background}

For at least three decades $\mathrm{CC}$ have been managing its processes under the recommendations of the World Federation of CC (WFCC, 2010). More recently OECD published the OECD Best Practice Guidelines (OECD BPG) (OECD, 2007) and subsequently promoted the CC selfevaluation publishing a set of three documents containing checklists based on those guidelines (OECD, 2009a, b, c). These two documents conveying recommendations, are not auditable documents thus not providing a reference for the conformity assessment leading to certification or accreditation.

France and Brazil have developed a standard for BRC certification and accreditation, respectively.

The French standard "NF S 96-900 - Qualité des Centres de Ressources Biologiques" (AFNOR, 2008) was based on the provisions of the OECD BPG and the withdrawn ISO 9001:2000 standard (ISO, 2000). In total, 31 French BRCs are certified under the NF S 96-900 standard (personal communication from Dominique Clermont). The Brazilian standard NIT-DICLA-061 (INMETRO, 2012) based on the recommendations of OECD BPG, the provisions of the ISO/EC 17025 standard (ISO/IEC, 2005) and the International Organisation for Standardisation (ISO) Guide 34 (ISO, 2009a), to our best knowledge, is not implemented in any CC. This standard also provides requirements for reference BM.

Some standards from the ISO conveying requirements for management systems apply to $\mathrm{BRC}$ and have been implemented in some CC. The ISO 9001 standard is implemented in 26 CC while the ISO/IEC 17025 standard was partially implemented in two. ISO Guide 34, although not implemented in this technical area, is also considered for CC producing reference BM (Betsu et al., 2007; Smith and Ryan, 2012).

ISO 9001 standard is seen as an appropriate standard for organizations with scope on biological resources as it provides a framework for the organizations to identify and document their processes. In fact, the process documentation helps to preserve, control and effectively change the know-how, as well as facilitating staff training especially for newcomers (Pascal et al., 2001). It is mainly focussed: on product and service requirements, on monitoring and evaluating processes, and on the continuous improvement of the management systems.

ISO 9001 standard also helps to undertake continual improvement in processes, to reassure owners of deposited $\mathrm{BM}$ of the $\mathrm{BRC}$ competence to manage their resources, and to assure clients of the supplied BM about the BRC's commitment to consistency and quality (Davis et al., 2012).

The ISO 17025 standard includes all the requirements from ISO 9001 standard relevant to the scope of laboratories performing essays and calibrations. Although, conformity to the 
ISO 17025 standard provisions do not mean, obviously, conformity with ISO 9001 standard. In the same way conformity of the BRC management system with the requirements of ISO 9001 does not prove, by itself, the competence of the BRC to produce technically valid data and results. This means that ISO 9001 certified BRC might not have enough technical competence to assess conformity of BM, as this standard is mainly concerned with what to do to achieve customer satisfaction (Barradas and Sampaio, 2011).

While the ISO 9001 standard requires that operations are conducted in accordance with the established procedures, the ISO standard 17025 goes beyond this, demanding not only the execution of technical work according to such established procedures, but also requiring confirmation of the technical competence of those involved in that work.

Despite their contribution in supporting quality (ISO 9001) and competence (ISO/IEC 17025) management systems, neither of the above-mentioned standards covers all BRC's operations. ISO/IEC 17025 standard in some other aspects is considered to go too far, demanding independent accreditation for each process and each preservation technique and authentication method (Smith and Ryan, 2012).

Inside of the Microbial Resource Research Infrastructure (MIRRI, www.mirri.org) ESFRI European Project a very important project has been developed under the workpackage 3 which looks to establish a common understanding of quality management system (QMS) and appropriate standards and best practice models. This paper intends to contribute to this discussion too.

\section{Method}

The goal of the presented work is to contribute to develop a standard providing requirements for managing the quality and competence of the BRCs.

The method followed was established to ensure that the developed standard conveys provisions (statements, requirements and recommendations) that can be consistently used by BRCs to ensure that BM preserved fits its purpose.

The method is underpinned by the principles of "credibility", "transparency", "alignment" and "consistency", looking for a high-quality standard, easily understandable by interested parties and conveying accurate relevant provisions.

Credibility was achieved by following international reference documents providing credible practices and transparency by making procedures available to the interested parties. Alignment was achieved by adopting a structure that enables the integration with other standards. Consistency within the standard and with other ISO standards was achieved by being in accordance with ISO Directives for standard development.

Consistency within the entire body of the document was also assured by clearly identifying the link between the standard objectives and the principles of the BM management and the link between each requirement and the relevant objective (ISEAL, 2014).

\subsection{Development procedures}

The standard setting procedures were established according to Figure 1.

3.1.1 Terms of reference. Terms of reference were established including the following elements: a justification study, the objectives of the standard, the scope, and a risk analysis on the implementation.

The justification study was performed in order to avoid standard duplication or overlap. Documentation of the existing standards and standards in process of development which meet all or part of the management needs of BRC was performed. Among them, the most widely implemented standards were identified.

The ISO 9001 and the NF S 96-900 standards, widely implemented in CC, were compared with the reference document for the BRC operation, the OECD BPG, which presents the most
A standard proposal for BRC 
IJQRM

34,2

150

Figure 1.

Procedure for the standard setting activities

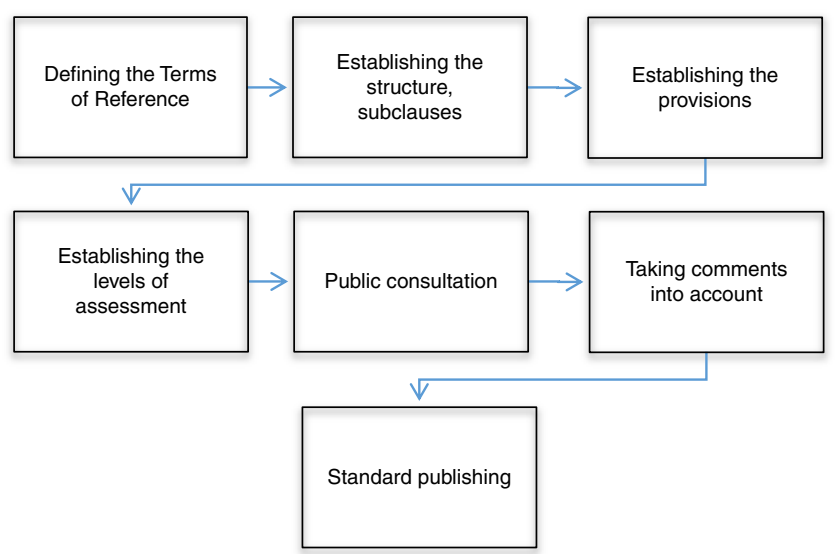

important issues the BRC shall consider in its management system. The existing voids among provisions, subjects covered, mandatory records and mandatory documented procedures were identified.

In order to establish the objectives that the standard aims to achieve, the principles that govern the activity of BRCs were first identified. These principles, guiding the management and authentication of BM, provide the foundation for the development of the standard. They can also serve as an anchor for guidance on decisions that BRCs need to make in unexpected situations.

Based on these, the objectives were clearly established and justified, defining the outcomes that the standard seeks to achieve. Clear objectives, aligned with the principles of BM management and authentication, are crucial since they are the pillars upon which the standard will be built.

The scope was defined, as well as the intended geographic application, after assessing the most important issues to address. The OECD BPG was the reference document.

An assessment of risks in implementing the standard was performed as well as how to mitigate for these. It included: the identification of factors that could have a negative impact on the ability of the standard to achieve its goals, unintended consequences that could arise from its implementation, and preventive actions that could be taken during the standard development to address these potential risks.

3.1.2 Establishing the type of standard, structure and rules for drafting. The type of standard was defined regarding the established structure (main clauses) and provisions. The technical provisions found during draft were documented and their relevance to the attainment of the objectives was evaluated.

The structure was defined looking for alignment with other standards with overlapping scope enabling the integration by BRCs of different disciplines.

Drafting followed the rules of the ISO/IEC Directives, part 1, consolidated ISO supplement - procedures specific to ISO (ISO/IEC, 2015) and ISO/IEC Directives, part 2 rules for the structure and drafting of International Standards (ISO/IEC, 2011), ensuring the uniformity of structure and style within the document and among ISO standards: identical structure and clause numbering, and the use of analogous and identical words to express analogous and identical provisions.

Other reference documents were also considered for drafting:

- CEN/CENELEC Guide 17 - guidance for writing standards taking into account micro, small and medium-sized enterprises needs (CEN/CENELEC, 2010); 
- ISO/IEC DIR IEC SUP - Directives supplement - procedures specific to IEC (ISO/IEC, 2012);

- ISO Guide 82 - guidelines for addressing sustainability in standards (ISO, 2014b);

A standard proposal for $\mathrm{BRC}$

- $\quad$ ISO Guide 59 - code of good practice for standardization (ISO/IEC, 1994); and

- WTO agreement on technical barriers to trade (WTO, 2008).

3.1.3 Establishing the provisions. The standard provisions were classified into "requirements", "recommendations" and "statements" (ISO/IEC, 2011). This facilitated the use of the correct terms within each provision, assured that all the requirements convey criteria and that the method to evaluate the fulfilment of the criteria was identified. This also made the standard easy to understand and facilitated the translation to other languages.

The requirements were established in order to be clear, objective and verifiable as previously said. They were expressed in terms of process management and performance criteria giving space for innovation and flexibility. When necessary explanations were added in order to facilitate transposition of pure performance requirements into practical solutions.

The use of terminology, in order to ensure consistency, was based on the "terms" and "definitions" presented in each of the reference documents and in the following documents:

- $\quad$ ISO 9000 standard - QMS - fundamentals and vocabulary (ISO, 2005);

- ISO/IEC Guide 2 - standardization and related activities - general vocabulary (ISO/IEC, 2004a);

- $\quad$ ISO Guide 73 - risk management - vocabulary (ISO, 2009b);

- OECD glossary of key terms in evaluation and results based management (OECD, 2010);

- ISO/IEC 17000 - conformity assessment - vocabulary and general principles (ISO/IEC, 2004b); and

- international vocabulary of metrology - basic and general concepts and associated terms - JCGM 200:2012 (BIPM, 2012).

In case of conflicting terminology, preference was given to the ISO documents.

In order to assure that: all requirements clearly contribute to the attainment of the standard goals, only requirements that are relevant to meet these outcomes are included and all the necessary requirements to address the defined goals are included, the link between the requirement, the leading objective and the related principle was identified.

To facilitate the link between the requirement and the appropriate objective, an intention declaration was made for each requirement or set of requirements, defining the desired outcome.

3.1.4 Establishing different levels of assessment. Because the dimension of the existing CC can vary widely and some requirements can be difficult to achieve for small collections, different levels of compliance were defined.

The requirements in the standard were classified into three different levels according to their degree of importance towards the objectives of the standard. The final standard will consist of a combination of baseline, medium and high-level requirements. To claim compliance with the standard within a given level, the BRC would apply for a conformity assessment within the defined level, fulfilling those requirements. The main goal is to foster continual improvement of the quality and competence management system of all the BRC.

3.1.5 Public consultation. Interested parties (e.g. auditors, heads of CC, quality managers of $\mathrm{CC}$, bio-industry, microbiologists and governmental officers) are invited to participate providing appropriate opportunities for valuable contributions in a transparent process whose different steps are identified in Figure 2. Comments are registered according to the 


\section{IJQRM}

34,2

\section{2}

Figure 2.

Procedure for the interested parties consultation/ participation

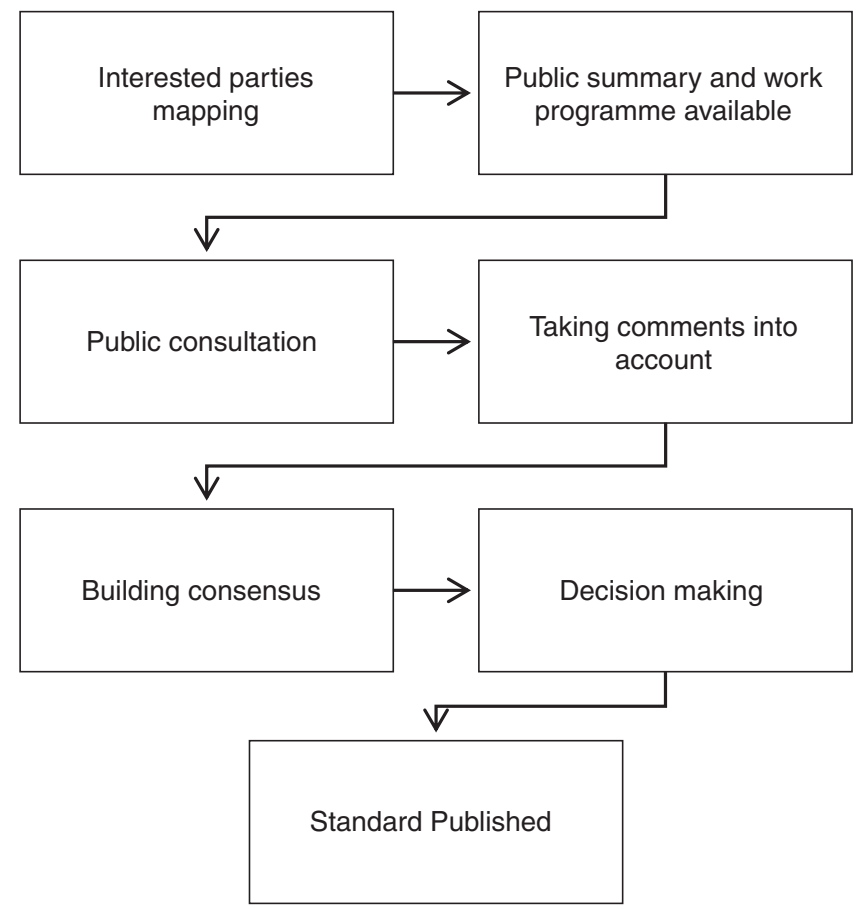

respective clause. They are analyzed and discussed within the assigned commission for decision. Comments that are not accepted will be justified and recorded. These records are made available to participants.

\section{Results}

\subsection{Results from the justification study}

Aiming to avoid standard duplication and overlap, the provisions from ISO 9001 standard (among the ISO standards the most sought by CC) and the NF S 96-900 standard (specifically designed for the certifications of BRCs managing biological resources from human or microorganism origins) were compared to the provisions from the reference document OECD BPG.

Existing voids were identified comparing the "scope", "mandatory records", "mandatory documented procedures" and "subjects covered" between the documents previously referred. In Tables I-IV are presented the most relevant findings. The chapter "Best Practice Guidelines on Biosecurity for BRC" presented on the OECD BPG was not compared with the mentioned standards since neither of them addresses this subject.

Although the ISO 9001 standard could apply to BRC it fails to address: key operational processes like shipping, handling and authentication of the BM, validation of methods and procedures, preparation and production of culture media, microbial BRC competence for the MB supply and preservation, specific needs for the management of documented information, biosecurity mechanisms and $\mathrm{CC}$ long term sustainability.

ISO 17025 standard is focused on competence, but as with ISO 9001 fails to address some of the key operational processes and specific management needs of BRCs. Some of these are: the handling and shipping of BM, the use and preparation of reagents, media and other supplies, the establishment of biosecurity mechanisms and the planning for the long term sustainability of the BRC. 
NF S 96-900

4 Organizational requirements

4.1 Long term sustainability

5 Premises

5.2 Construction and operation

7.1 Compliance with internal documentation

10.2 Accession

11.1 Methodology (of preservation)

11.2 Stock control of the preserved biological materials

11.3 Storage of preserved biological materials

11.4 Validation of methods and procedures

12 Supply of material

12.2 Availability of the biological material ordered

12.3 Information provided with the biological material supplied

12.5 Invoicing for supply charges

12.6 Traceability of biological materials supplied

12.7 Handling complaints and anomalies

12.8 Refunds

13.1 Purpose

13.2 Responsibility
ISO 9001

4.1 Long term sustainability

5.1 Biological resource centre operations

5.2 Construction and operation

5.3 Access

7.1 Compliance with internal documentation

8 Data and informatics

8.1 Data management

8.2 Data processing

9 Preparation of media and reagents

10 Accession of deposit to the BRC

10.1 Receipt and handling of biological materials

10.2 Accession

10.3 Quality checks on the biological material

11 Preservation and maintenance

11.1 Methodology (of preservation)

11.2 Stock control of the preserved biological materials

11.3 Storage of preserved biological materials

11.4 Validation of methods and procedures

12 Supply of material

12.1 Order placement

12.2 Availability of the biological material ordered

12.3 Information provided with the biological material supplied

12.4 Packaging

12.5 Invoicing for supply charges

12.6 Traceability of biological materials supplied

12.8 Refunds

12.9 Confidentiality
A standard proposal for $\mathrm{BRC}$

153

Table I.

Clauses of OECD GPG applied to all BRC that have no correspondence on $\mathrm{NF}$ S 96-900 and ISO 9001

\section{NF S 96-900}

10.1 Long-term preservation

11.2 User validation

11.5 Traceability of hazardous biological materials

12 Micro-organism BRCs compliance with national and international law

12.1 Classification of micro-organisms according to the risk groups

12.2 Quarantine regulations

12.3 Intellectual property rights

12.4 Safety information provided to the recipient of micro-organisms

12.5 Control of distribution of hazardous microorganisms
ISO 9001

10.1 Long-term preservation

11.2 User validation

11.5 Traceability of hazardous biological materials

12 Micro-organism BRCs compliance with national and international law

12.1 Classification of micro-organisms according to the risk groups

12.2 Quarantine regulations

12.3 Intellectual property rights

12.4 Safety information provided to the recipient of micro-organisms

12.5 Control of distribution of hazardous microorganisms
Table II.

Clauses of OECD GPG applied to the microbial domain

that have no

correspondence on $\mathrm{NF}$ S $96-900$ and ISO 9001

The French standard NF S 96-900 does not cover critical issues such as biosecurity mechanisms, long term sustainability and some process key aspects such as quarantine regulations, BM supply, validation of methods and procedures.

The French standard NF S 96-900 does not include records such as the "Minimum", "Recommended" and "Full data set" for BM, results of audit reviews and record reviews, 


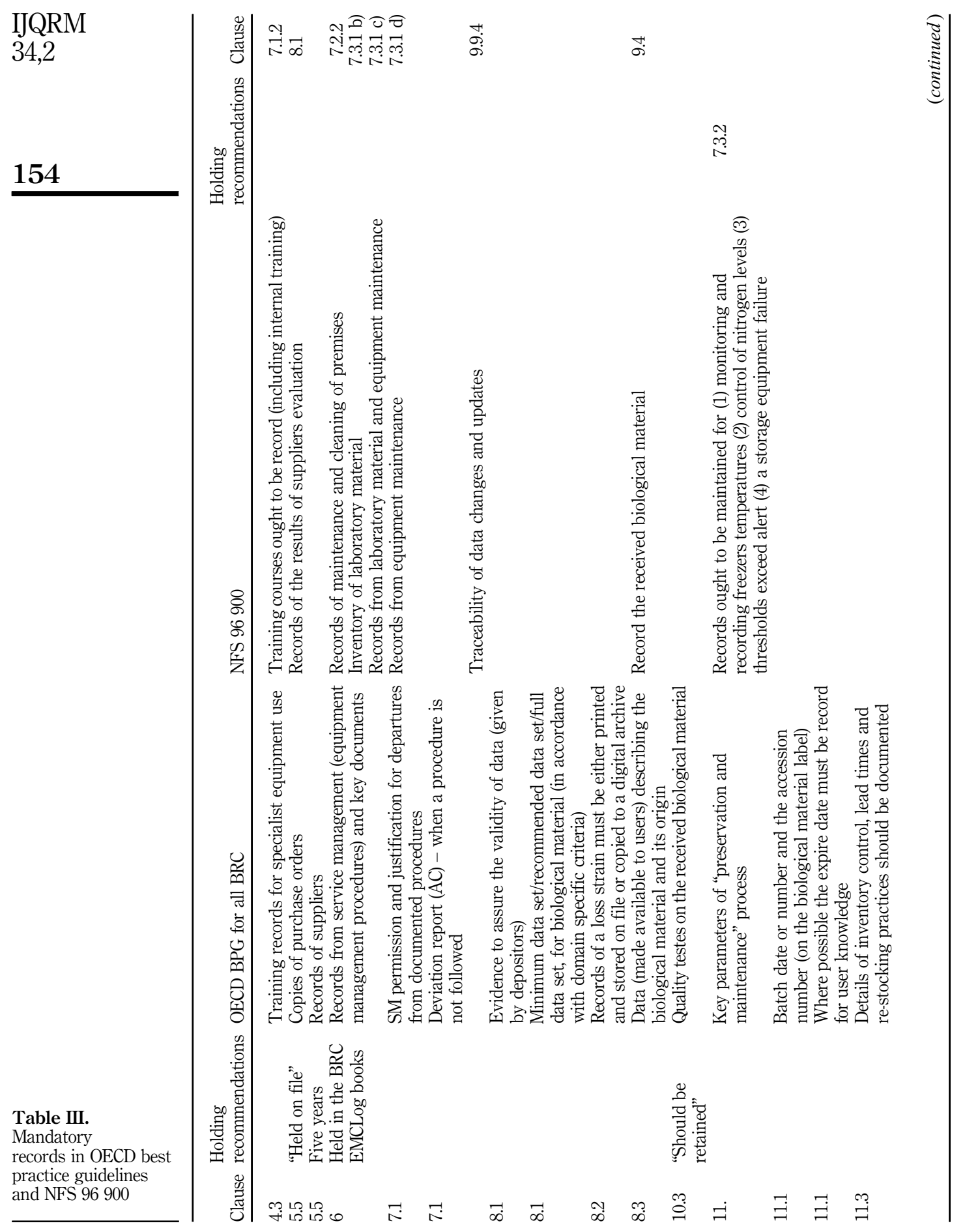




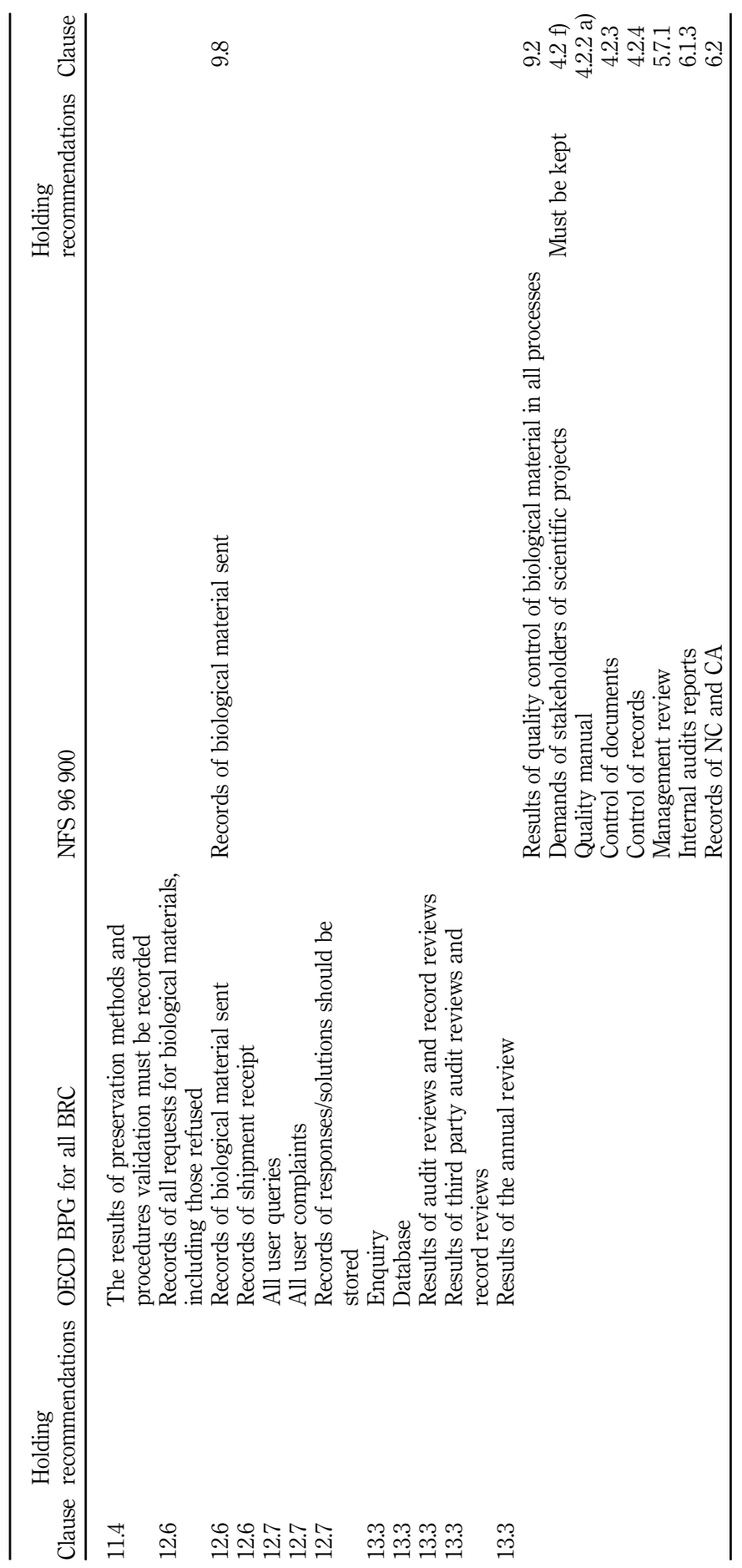

A standard proposal for BRC

155

Table III. 
IJQRM

34,2

156

some records of shipment, batch date or number and the accession number (on the BM label), user queries and complaints, results of quality checks on preserved material, media and reagents labelling with batch number and expiry date, evidence given by depositors to assure the validity of data. The records recommended by the OECD BPG not addressed in the NF S 96-900 standard are presented in Tables III and IV.

Some examples of the documented information recommended by the OECD BPG that is not included in the French standard are: the documentation of the safe operational level or safety limit for the resources available, the authorization to use specialist equipment, the nature of the BM held, cleaning and decontamination procedures, procedures for all preparations used in the growth and/or maintenance of the living BM held, procedures for storage, methods used for the risk assessment.

\subsection{Principles for the management and authentication of BM}

The principles for the BM management and authentication were identified and are presented in Figure 3.

\subsection{Objectives and scope}

The objectives and scope of the standard were defined as follows:

Objectives: The main objective of the present standard is to provide general and specific provisions for $\mathrm{BRC}$ acting in the microbial domain to ensure: effective management of its processes, competence of the personnel with laboratorial responsibilities, reliability and reproducibility of the results of preservation and authentication techniques and the existence of effective procedures in biosafety and biosecurity.

It also provides the necessary reference for accreditation of $\mathrm{BRC}$ by competent bodies, as a means to achieve mutual recognition among BRC and client confidence.

Scope: The present standard specifies the requirements for a BRC management system in order to demonstrate its competence to perform preservation and authentication of microorganisms, addressing applicable statutory and regulatory requirements, meet and enhance all interested parties' satisfaction through the effective application of the management system, including processes for continual improvement of the management system and the assurance of conformity to customer and applicable statutory and regulatory requirements.

It applies to all BRC that receive, preserve, store and supply biological material of microbial origin.

\subsection{Type of standard, structure and content}

The standard is a type A management system standard (MSS) conveying requirements for competence of personnel performing technical work.

Looking for alignment with other standards with overlapping scope and enabling the integration of different disciplines, the "high level structure" (HLS), "identical sub-clause titles",

\begin{tabular}{|c|c|c|c|c|c|}
\hline Clause & $\begin{array}{l}\text { Holding } \\
\text { time }\end{array}$ & OECD BPG on microbiological domain & NF S 96900 & $\begin{array}{l}\text { Holding } \\
\text { time }\end{array}$ & Clause \\
\hline 8. & & $\begin{array}{l}\text { Media (and reagents) should be labelled with batch } \\
\text { number and expire date }\end{array}$ & & & \\
\hline 10.2 & & $\begin{array}{l}\text { Results of quality checks on preserved material } \\
\text { Individual records of all requests for hazardous biological } \\
\text { materials, including those refused }\end{array}$ & & & \\
\hline 11.5 & & Individual records of hazardous biological material sent & & & \\
\hline 12.3 & & $\begin{array}{l}\text { Terms and conditions for further distribution of deposited } \\
\text { micro-organisms }\end{array}$ & & & \\
\hline
\end{tabular}

Table IV.

Mandatory records for OECD BPG on Microbial Domain and NF S 96900
Terms and conditions for further distribution of deposited 


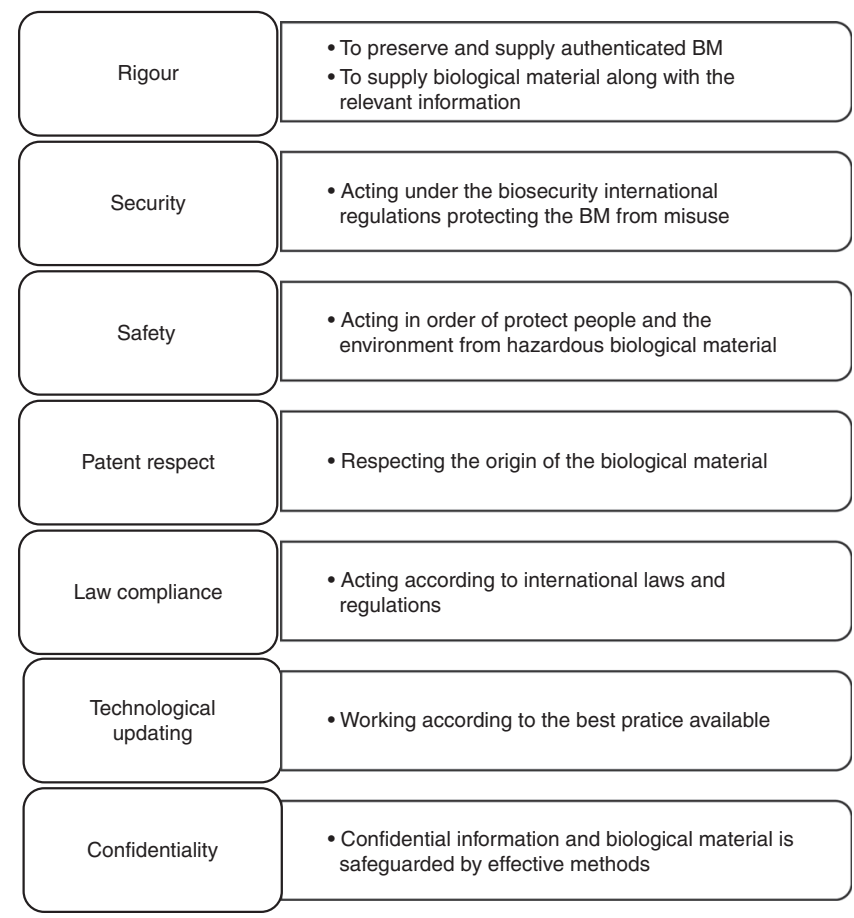

A standard proposal for $\mathrm{BRC}$

Figure 3.

Principles of the biological material management and authentication and its relation to the $\mathrm{BRC}$

"identical text" and "common terms and core definitions" from the Annex SL (ISO/IEC, 2015), were adopted.

This integration idea started in the early 1990s when the Technical Management Board required the Technical Commission (TC) 176 and the TC 207 to work together in order to ensure alignment of their standards. This work was expanded by the Joint Technical Coordination Group from ISO which had made huge progress towards the alignment between standards. This structure, mandatory for MSS, is addressed in the "Consolidated ISO Supplement” within the ISO/IEC Directive Part 1 (ISO/IEC, 2015).

The standard content was established upon: the provisions of the OECD best practice guidelines (OECD, 2007), the provisions of the standards currently implemented in BRC, standards for BRCs in process of development and standards having provisions applicable to BRCs. Appropriate and relevant requirements from those standards and almost all provisions of OECD BPG were assembled into this new ISO-consistent standard. The NF S 96-900 Draft (AFNOR, 2013) has the same provisions as the NF S 96-900 (AFNOR, 2008).

The original text of ISO DIS 9001 (ISO, 2014c) was widely adopted.

The documents considered for drafting were:

- ISO DIS 9001 - QMS, requirements (ISO, 2014c).

- ISO/IEC 17025 - general requirements for the competence of testing and calibration laboratories (ISO/IEC, 2005).

- ISO 15189 - medical laboratories - requirements for quality and competence (ISO, 2012).

- ISO guide 34 - general requirements for the competence of reference material producers (ISO, 2009a). 
IJQRM

34,2

158

- NIT DICLA 61 - Requisitos sobre a acreditação dos laboratórios de ensaio e dos produtores de materiais de referência dos centros de recursos biológicos (INMETRO, 2012).

- ISO 11133 - microbiology of food, animal feed and water - Preparation, production, storage and performance testing of culture media (ISO, 2014a, b, c).

- NP EN 12128 - biotechnology. Laboratories for research, development and analysis. Containment levels of microbiology laboratories, areas of risk, localities and physical safety requirements (IPQ, 2000).

- ISO 15190 - medical laboratories - requirements for safety (ISO, 2003).

- NP EN 1619 - large-scale process and production. General requirements for management and organization for strain conservation procedures (IPQ, 1999).

- NF S 96-900 - Qualité des Centres de Ressources Biologiques (AFNOR, 2008).

- NF S 96-900 Draft - quality management of biobanks/BRC and quality of biological resources (AFNOR, 2013).

- ISO/FDIS 14001:2015 - environmental management systems - requirements with guidance for use (ISO, 2015).

The structure and sub-clauses of the standard are presented in Table V. The main structure is based in Annex SL HLS. Additional sub-clauses, based on ISO/DIS 9001 and OECD BPG, creating the framework to address specific elements from the BRC activity and essential for the construction of a logic structure, were added.

\subsection{Levels of compliance}

Complying with all the requirements in the present standard could be a very difficult task for BRCs. The noncompliance with some of the requirements can block its access to certification. In order to overcome this risk, promoting the uptake of the standard, different levels of compliance were established based on the risk level for the: BRC competence, BM quality, biosafety and biosecurity.

The requirements in the standard are classified in three different levels of achievement, as presented in Table VI: baseline, medium and high level.

Baseline level requirements are the minimum compliance that quality and competence management systems need to meet to be considered a BRC, after integrating the GBRCN. $\mathrm{BRC}$ at this level have to make a commitment to comply with the medium level within three years, developing an improvement programme. The same steps are taken for BRC at the medium level to reach the high-level compliance.

When applying for the certification, the BRC will apply for one of the three levels of compliance. Only the correspondent requirements will be audited.

Auditors should have relevant experience in the field and specific training.

\section{Conclusion}

OECD recommends the creation of a global BRC network with each element operating under certification or accreditation schemes. Despite the availability of important guidelines, no relevant international normative document for certification or accreditation, covering all the activities of BRCs, exists.

The large majority of the certified $\mathrm{CC}$, in the microbiological domain, had opted for certification by ISO 9001 standard. Two CC embarked in accreditation by ISO/IEC 17025 and in France a standard was specifically developed for the BRC management activities. Brazil had also developed its own reference document. However none of these standards 


\begin{tabular}{|c|c|c|c|}
\hline Clauses & Sub-clauses & Title & A standard \\
\hline 1 & & Scope & $\mathrm{BRC}$ \\
\hline 2 & & Normative references & \\
\hline 3 & & Terms and definitions & \\
\hline \multirow[t]{5}{*}{4} & & Context of the BRC & \\
\hline & 4.1 & Understanding the BRC and its context & \\
\hline & 4.2 & Understanding the needs and expectations of interested parties & 159 \\
\hline & 4.3 & Determining the scope of the $\mathrm{C} \& \mathrm{Q}$ management system & \\
\hline & 4.4 & C\&Q management system (and its processes) & \\
\hline \multirow[t]{6}{*}{5} & & Leadership & \\
\hline & 5.1 & Leadership and commitment & \\
\hline & 5.2 & (C\&Q) Policy & \\
\hline & 5.3 & Biological material accession policy & \\
\hline & 5.4 & Biological material supply policy & \\
\hline & 5.5 & $\mathrm{BRC}$ roles, responsibilities and authorities & \\
\hline \multirow[t]{6}{*}{6} & & Planning (for the C and Q management system) & \\
\hline & 6.1 & Actions to address risks and opportunities & \\
\hline & 6.2 & Biosafety & \\
\hline & 6.3 & Biosecurity & \\
\hline & 6.4 & C\&Q objectives and planning to achieve them & \\
\hline & 6.5 & Planning of changes & \\
\hline \multirow[t]{6}{*}{7} & & Support & \\
\hline & 7.1 & Resources & \\
\hline & 7.2 & Competence & \\
\hline & 7.3 & Awareness & \\
\hline & 7.4 & Communication & \\
\hline & 7.5 & Documented information & \\
\hline \multirow[t]{8}{*}{8} & & Operation & \\
\hline & 8.1 & Operational planning and control & \\
\hline & 8.2 & Selection, verification and validation of technical procedures & \\
\hline & 8.3 & Determination of requirements for the biological material preservation and supply & \\
\hline & 8.4 & Control of externally provided products and services & \\
\hline & 8.5 & Biological material provision & \\
\hline & 8.6 & Release of biological material & \\
\hline & 8.7 & Control of nonconforming process outputs, products and services & \\
\hline \multirow[t]{4}{*}{9} & & Performance Evaluation & \\
\hline & 9.1 & Monitoring, measurement, analysis and evaluation & \\
\hline & 9.2 & Internal audit & \\
\hline & 9.3 & Management review & Table V. \\
\hline \multirow[t]{4}{*}{10} & & Improvement & Structure and \\
\hline & 10.1 & General & sub-clauses of the \\
\hline & 10.2 & Nonconformity and corrective action & BRC quality and \\
\hline & 10.3 & Continual improvement & competence MSS \\
\hline
\end{tabular}

cover fundamental issues for the BRC operation, thus having a major impact on the efficient preservation and supply of authenticated BM, biosecurity assurance, the long term sustainability of $\mathrm{BRC}$ and biodiversity preservation.

The standard presented here is an innovative document, underpinned by the principles established for the management and authentication of BM and based on the provisions of relevant international documents applied to BM preservation, authentication and supply. It encompasses though all the key-activities and critical aspects of BRCs. It is being developed within a credible and transparent process guided by the provisions of ISO for standard development. It is aligned with the ISO MSSs and the expectations and wishes of interested parties are being taken into account as well as the state of the art. 
$\mathrm{IJQRM}$

34,2
Level of

compliance Shall fulfil the requirements related to

$\begin{array}{ll}\text { Baseline } & \begin{array}{l}\text { Process management } \\ \text { Competence of the personnel with laboratorial responsibilities }\end{array}\end{array}$

Competence of the personnel with
Reliable preservation techniques

160

Authentication of supplied material

Effective procedures on biosafety

Identification of the strains with high risk on biosecurity

Planning of effective procedures on biosecurity (minimum security necessary if high risk strains are held)

Planning of effective procedures to assure the long term sustainability

Planning of effective procedures to face disasters

Table VI. Medium

Effective procedures on biosecurity in implementation

Levels of achievement and associated requirements that the BRC shall fulfil to claim for compliance

Assurance of the long term sustainability in implementation

Contingency plan

High level Infrastructure designed according to the available best practice

Effective procedures on biosecurity

Assurance of the long term sustainability

By adhering to these standard provisions, that constitute credible and recognized good practices for the BM supply and preservation, BRC will help to strength their sustainability ensuring that their work results in measurable progress towards the global objective of preserving and supplying authenticated high quality BM, through a worldwide network of BRCs, to biotechnology, contributing to the development of new medicines, new environmental remediation and agriculture technologies.

As this standard can be the reference document against which the competence and quality of the BRCs can be assessed, we believe that it will be the launch pad for the establishment of the so awaited GBRCN, facilitating the cooperation among BRCs and other interested parties, promoting the exchange of information and expertise and harmonizing procedures.

The results of this research are being considered in the working group two of the ISO/TC 276 Biotechnology, which is initiating the development of a standard for BRCs and biobanks.

\section{References}

AFNOR (2008), "NF S96-900 - Qualité des Collections de Ressources Biologiques (CRB) - Système de management d'un CRB et qualité des ressources biologiques d'origine humaine et microbienne", Association Française de Normalisation, Paris.

AFNOR (2013), "NF S 96-900 Draft - quality management of biobanks/biological resource centres (BRCs) and quality of biological resources", Association Française de Normalisation, Paris.

Barradas, J. and Sampaio, P. (2011), "ISO 9001 and ISO 17025 standards in a metrology laboratory", Livro de Actas, em formato CD-ROM, da 14th Toulon-Verona Conference, Alicante, ISBN 978-88904327-1-2, pp. 143-152.

Betsu, F., Luzergues, A., Carter, A., Geary, P., Riegman, P., Clark, B., Morente, M., Vaught, J., Ghirr, R. and Druez-Verité, C., Marble Arch Working Group on International Biobanking (2007), "Towards norms for accreditation of biobanks for human health and medical research: compilation of existing guidelines into an ISO certification/accreditation norm-compatible format", Quality Assurance Iournal, Vol. 11 Nos 3-4, pp. 221-294.

BIPM (2012), International Vocabulary of Metrology - Basic and General Concepts and Associated Terms, JCGM 200:2012, VIM 3rd ed., Bureau International de Poids et Mesures, Sévres.

Boundy-Mills, K. (2012), "Yeast culture collections of the world: meeting the needs of industrial researchers", Journal of Industrial Microbiology Biotechnology, Vol. 39 No. 5, pp. 673-680. 
CEN/CENELEC (2010), "CEN/CENELEC Guide 17 - guidance for writing standards taking into account micro, small and medium-sized enterprises (SMEs) needs", European Committee for Standardization and European Committee for Electrotechnical Standardization, Brussels.

Davis, E., Hampson, K., Bray, C., Dixon, K., Ollier, B. and Yuille, M. (2012), "Selection and implementation of the ISO 9001 standard to support biobanking research infrastructure development", Biopreservation and Biobanking, Vol. 10 No. 2, pp. 1-7.

INMETRO (2012), "NIT-DICLA-061, Rev.2, - Requisitos sobre a acreditação dos laboratórios de ensaio e dos produtores de materiais de referência dos centros de recursos biológicos, Divisão de Acreditação de Laboratórios", Instituto Nacional de Metrologia e Qualidade, Rio de Janeiro.

IPQ (1999), "NP EN 1619:1999 - Biotecnologia. Processos e produção em grande escala. Requisitos gerais para a gestão e organização dos procedimentos para conservação de estirpes", Instituto Português da Qualidade, Lisboa.

IPQ (2000), "NP EN 12128:2000 - Biotecnologia. Laboratórios de investigação, desenvolvimento e análises Níveis de confinamento de laboratórios de microbiologia, áreas de risco, locais e requisitos físicos de segurança", Instituto Português da Qualidade, Lisboa.

ISEAL (2014), "Setting social and environmental standards - code of good practice", Version 6.0, Iseal Alliance, London, available at: www.isealalliance.org/sites/default/files/ISEAL $\% 20$ Standard $\%$ 20Setting \%20Code \%20v6\%20Dec\%202014.pdf (accessed 21 July 2015).

ISO (2000), "EN ISO 9001:2000 - quality management systems - requirements organization for standardization", Organization for Standardization, Geneva (revised by ISO 9001:2008).

ISO (2003), "ISO 15190:2003 - medical laboratories - requirements for safety", International Organization for Standardization, Geneva.

ISO (2005), "ISO 9000:2005 - quality management systems - fundamentals and vocabulary", International Organization for Standardization, Geneva.

ISO (2009a), "ISO Guide 34:2009 - general requirements for the competence of reference material producers", International Organization for Standardization, Geneva.

ISO (2009b), "ISO Guide 73:2009 - risk management - vocabulary", International Organization for Standardization, Geneva.

ISO (2012), "15189:2012 - medical laboratories - requirements for quality and competence", International Organization for Standardization, Geneva.

ISO (2014a), "ISO 11133:2014 - microbiology of food, animal feed and water - preparation, production, storage and performance testing of culture media”, International Organization for Standardization, Geneva.

ISO (2014b), "ISO Guide 82:2014 - guidelines for addressing sustainability in standards", International Organization for Standardization, Geneva.

ISO (2014c), "ISO DIS 9001 - quality management systems, requirements", International Organization for Standardization, Geneva.

ISO (2015), "ISO/FDIS 14001:2015 - environmental management systems - requirements with guidance for use", International Organization for Standardization, Geneva.

ISO/IEC (1994), "ISO/IEC Guide 59:1994 - code of good practice for standardization", International Organization for Standardization and International Electrotechnical Commission, Geneva.

ISO/IEC (2004a), "ISO/IEC Guide 2:2004 - standardization and related activities - general vocabulary", International Organization for Standardization and International Electrotechnical Commission, Geneva.

ISO/IEC (2004b), "ISO/IEC 17000:2004 - conformity assessment - vocabulary and general principles", International Organization for Standardization and International Electrotechnical Commission, Geneva.

ISO/IEC (2005), "ISO/IEC 17025:2005 - general requirements for the competence of testing and calibration laboratories", International Organization for Standardization, Geneva.

ISO/IEC (2011), "ISO/IEC Directives, part 2 - rules for the structure and drafting of international standards", International Organization for Standardization and International Electrotechnical Commission, Geneva. 
IJQRM

34,2

ISO/IEC (2012), "ISO/IEC Directives supplement - procedures specific to IEC", International Electrotechnical Commission, Geneva.

ISO/IEC (2015), ISO/IEC Directives, Part 1 - Consolidated ISO Supplement - Procedures Specific to ISO, 6th ed., International Organization for Standardization and International Electrotechnical Commission, Geneva.

Lima, N. (2007), "Centros de recursos biológicos: novos desafios para as coleções de culturas", in Nunes, M.L. and Bandarra, N.M. (Eds), Micologia, avanços no conhecimento, Conferência Plenária Convidada apresentada no $5^{\circ}$ Congresso Brasileiro de Micologia, Recife, 12-16 Novembro, ISBN 978-85-7315-444-3, Universitária da UFPE, Recife, pp. 173-180.

OECD (2001), Biological Resource Centres - Underpinning the Future of life Sciences and Biotechnology”, ISBN 92-64-18690-5 932001041 P, OECD, Paris.

OECD (2004), OECD Global Forum Knowledge Economy: Biotechnology. Guidance for the Operations of Biological Research Centres. Certification and Quality Criteria for BRCs, The Organisation for Economic Co-operation and Development, Paris.

OECD (2007), "OECD best practice guidelines for biological resource centres", OECD, Paris.

OECD (2009a), "Self evaluation checklist for the OECD best practice guidelines for biological resource centres - general best practice guidelines for all BRCs", Version 1.0, OECD.

OECD (2009b), "Self evaluation checklist for the OECD best practice guidelines for biological resource centres. General best practice guidelines for the micro-organism domain", Version 1.0, OECD.

OECD (2009c), "Self evaluation checklist for the OECD best practice guidelines for biological resource centres. General best practice guidelines on biosecurity", Version 1.0, OECD.

OECD (2010), Glossary of Key Terms in Evaluation and Results Based Management, OECD, Paris.

Pascal, P., Chalochet, A. and Damour, O. (2001), "Banque de cornées de Lyon: du diagnostic qualité à la certification ISO 9001”, Pathologie Biologie, Vol. 49 No. 10, pp. 846-853.

Santos, I. and Lima, N. (2001), "Criteria followed in the establishment of a filamentous fungal culture collection - Micoteca da Universidade do Minho", World Iournal of Microbiology and Biotechnology, Vol. 17 No. 3, pp. 215-220.

Smith, D. and Ryan, M. (2012), "Implementing best practices and validation of cryopreservation techniques for microorganisms scientific", The Scientific World Journal, Vol. 2012, Article ID 805659, pp. 1-9, doi: $10.1100 / 2012 / 805659$.

WFCC (2010), "World federation for culture collections guidelines for the establishment and operation of culture collections of microorganisms", available at: www.wfcc.info/pdf/WFCC_Guidelines_ Version_Third_Edition.pdf (accessed 21 July 2015).

WTO (2008), "WTO technical barriers to trade (TBT) agreement annex 3, code of good practice for the preparation, adoption and application of standards", available at: www.wto.org/english/docs_ e/legal_e/17-tbt_e.htm (accessed 21 July 2015).

\section{Further reading}

ISO (2008), "EN ISO 9001:2008 - quality management systems - requirements", International Organization for Standardization, Geneva.

\section{Corresponding author}

Nelson Lima can be contacted at: nelson@ie.uminho.pt

For instructions on how to order reprints of this article, please visit our website:

www.emeraldgrouppublishing.com/licensing/reprints.htm

Or contact us for further details: permissions@emeraldinsight.com 